УДК 656.7.052

\title{
Systems of Automated Exploration \\ of Radio-Technical Systems \\ of the Aviation Flights Service
}

Viktor G. Mashkov,

Oleg Y. Buhtoyarov and Petr A. Dmitriev*

Military Education and Research Centre of Military-Air Forces

«Military-Air Academy

Named After Professor N.E. Zhukovsky and Yu.A. Gagarin»

54a Starykh Bolshevikov Str., Voronezh, 394064, Russia

Received 17.03.2017, received in revised form 20.03.2017, accepted 08.04.2017

There is a review of the way of training and retraining of radio-technical systems operators by using system of automated exploration, which is able to identify and manage the individual training program.

Keywords: radio-technical support, radio-technical systems, ergatic element, exploration.

Citation: Mashkov V.G., Buhtoyarov O.Y., Dmitriev P.A. Systems of automated exploration of radio-technical systems of the aviation flights service, J. Sib. Fed. Univ. Eng. technol., 2017, 10(4), 457-466. DOI: 10.17516/1999-494X-2017-10-4-457-466.

(C) Siberian Federal University. All rights reserved

* Corresponding author E-mail address: mailto:mvgblaze@mail.ru, mr-buhtoyrov@ya.ru 


\title{
Системы автоматизированного освоения
}

\section{радиотехнических систем}

\section{обеспечения полетов авиации}

\author{
В.Г. Машков, О.Ю. Бухтояров, П.А. Дмитриев \\ Военный учебно-научный центр Военно-воздушных сил \\ «Военно-воздушная академия \\ имени профессора Н.Е. Жуковского и Ю.А. Гагарина» \\ Россия, 394064, Воронеж, ул. Старых Большевиков, 54 а
}

Рассматривается способ подготовки и переподготовки операторов радиотехнических систем с помощью системы автоматизированного освоения, способной определять и управлять программой индивидуальной подготовки.

Ключевые слова: радиотехническое обеспечение, радиотехнические системы, эргатический элемент, освоение.

The modern level of development of computer technology, information technology and distance learning methodology in some cases allows to simulate human as an element of the complex humanmachine system, to explore his properties and provide the automated exploration of such system to increase efficiency of its functioning. This fact leads to an increased interest in human participation in radio-technical systems (RTS) and solving a problem of quality improving of their functioning. Insufficient knowledge of real RTS and the active human participation in the functionality process don't allow to describe a behavior of RTS. Functionality analysis of the radio-technical service system (RSS) as a military-technical shows (Fig. 1), that RTS efficiency directly depends on functionality quality of the ergatic element (EE) of the system.

That fact forms for researchers the problem of quality improving of EE functioning and requires the development of theory and practice of technologies synthesis, that allow to increase the EE quality level.

By analyzing the statistic of RTS failures, which reflects the percentage distribution of the failure causes, it can be concluded, that under the current system of specialists training the equipment failures reach $28 \%$ (Fig. 2), and failures, caused by personnel errors, reach $72 \%$ from the total number of RTS failures. According to the official data of ICAO this indicator reaches $80 \%$. And the greatest quantity of human-caused failures (36\%) is connected with insufficient quality of equipment exploration.

The analysis of RTS exploration methods in order to find effective ways of quality increasing of this process shows, that main exploration methods of such systems are the special addition theoretical and simulator training. The main task of simulator training is a skills inculcation of work with technical system. With the undoubted advantages of the modern simulator training their use is connected with a number of significant disadvantages, that don't allow to generalize the process of quality increasing of EE in RTS. The main disadvantage is the absence of effective means of optimal management and operational control of the learning process. So, in existing technical training means there is no interactive systems, which organize the dialog interaction and manage the RTS exploration process, that doesn't allow rapidly and objectively to assess the level of its qualification, taking into 


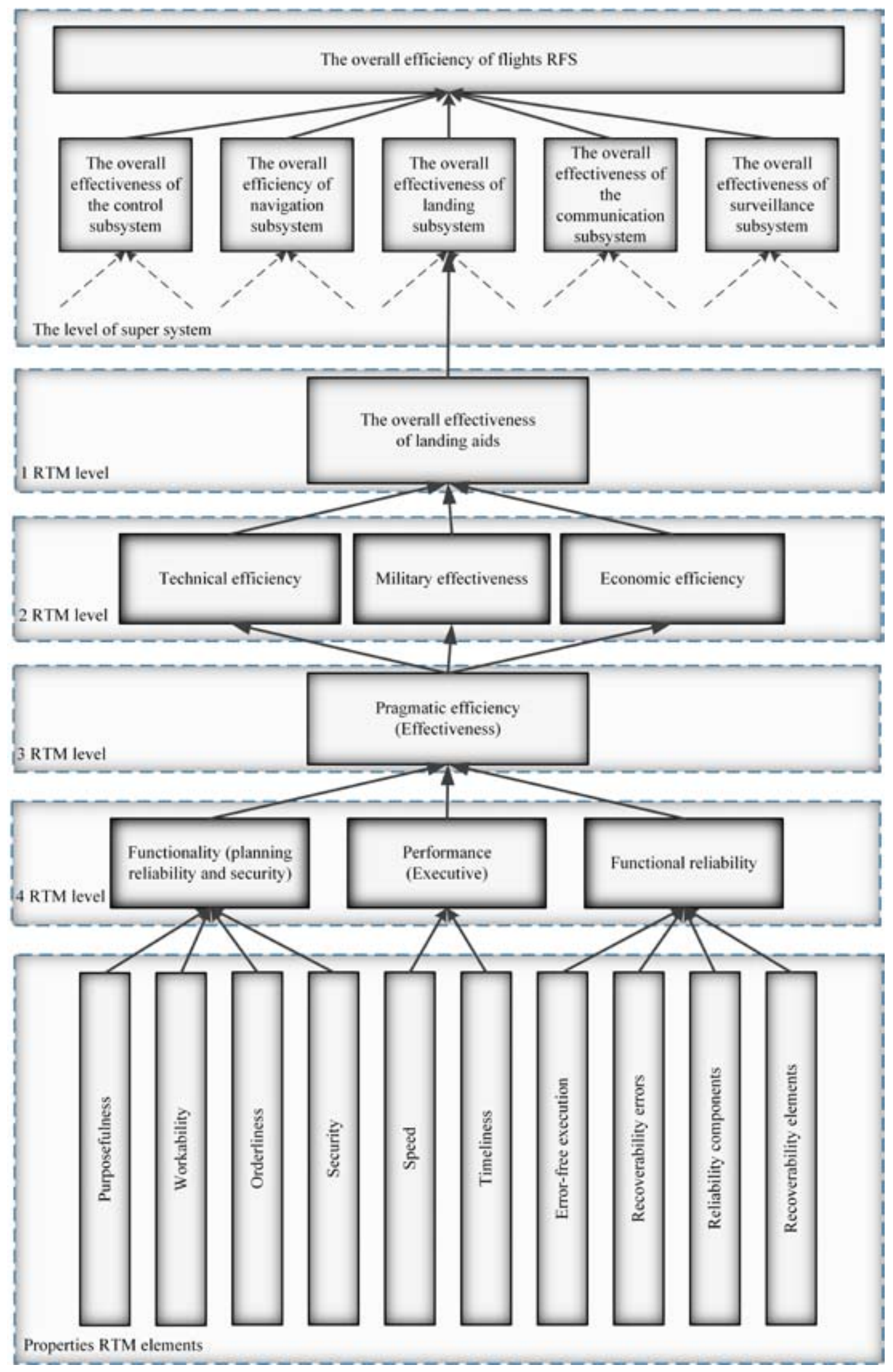

Fig. 1. The structure for assessing the effectiveness of RTS 


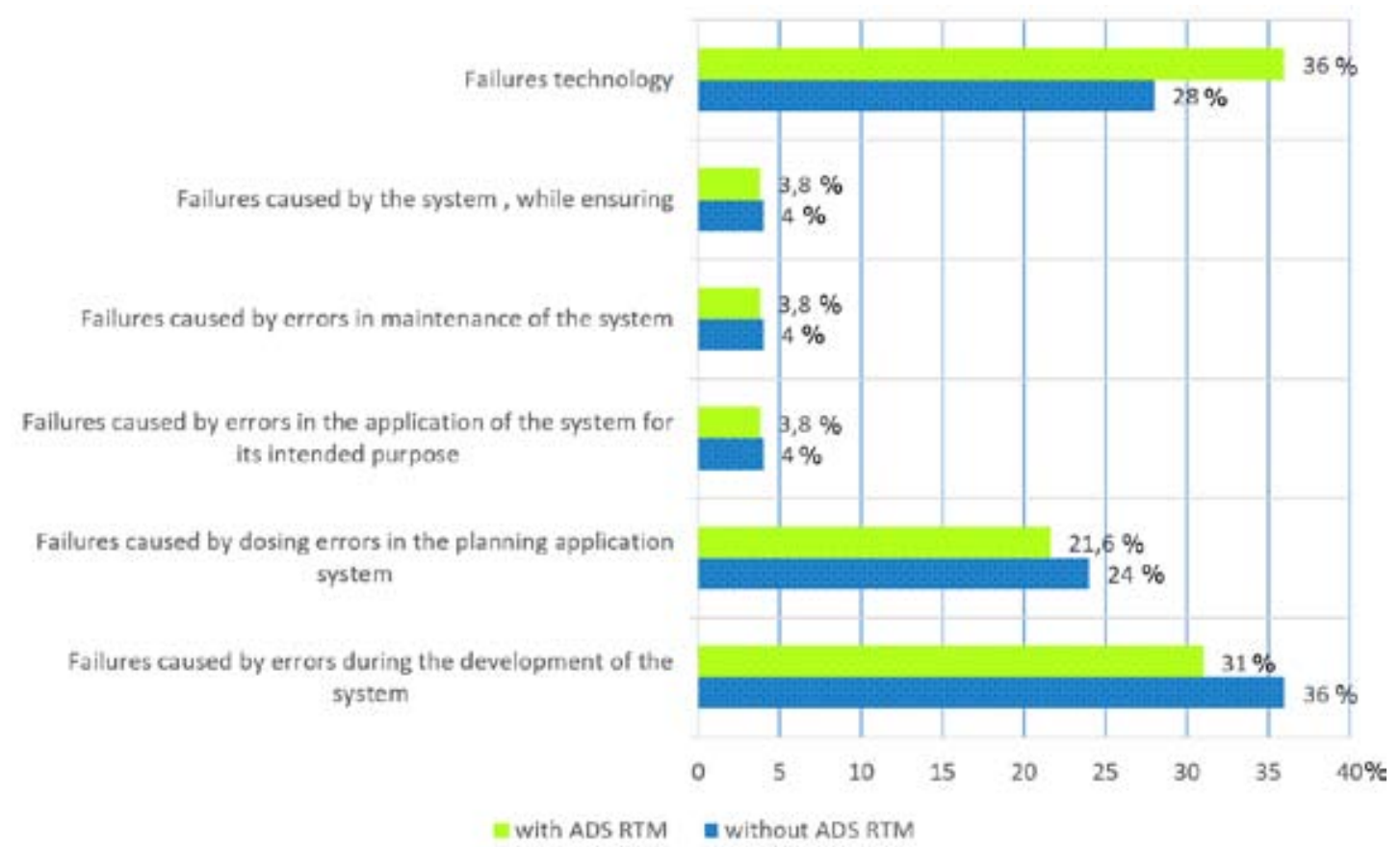

Fig. 2. Statistics of failure RTS

account individual characteristics of EE, and, if it's necessary, to increase that level for limited time to a predetermined value.

This article is devoted to the discussion of the system of automated exploration RTS (SAE RTS).

\section{Functional purpose and features of the SAE RTS construction}

According to [1] the term "to learn" the object means to learn it and to learn to work with it. Tuition (training, retraining) lies in the base of the exploration process, i.e exploration of specific knowledges, acquisition of skills, that are necessary for effective functionality of user-specialist (US) the user, who is relative to the computer, and the specialist, who is relative to that subject area as a part of RTS.

The SAE RTS, that have being developed, must consider: individual features of US; the level of formed knowledges; the level of practical skills of the work on the technique; time, allotted on the technique exploration; the necessary level of the preparation profile. In addition, such a system should be adaptive. Under adaptation we will understand the system's ability to adapt to changing internal and external conditions by changing its structure and parameter values.

Nowadays, military knowledges are getting old not together with people, as it was early, but faster. Theoretical knowledge require significant replenishment through $8 . .10$ years, practical knowledges should also be updated through $6 . . .7$ years, and practical skills - more often [2]. According to this content, the main problem of RTS exploration is continuous and qualitative acquiring of new knowledge, updating and strengthening of skills of the work with the technique for a limited time, under the conditions of the military unit. 


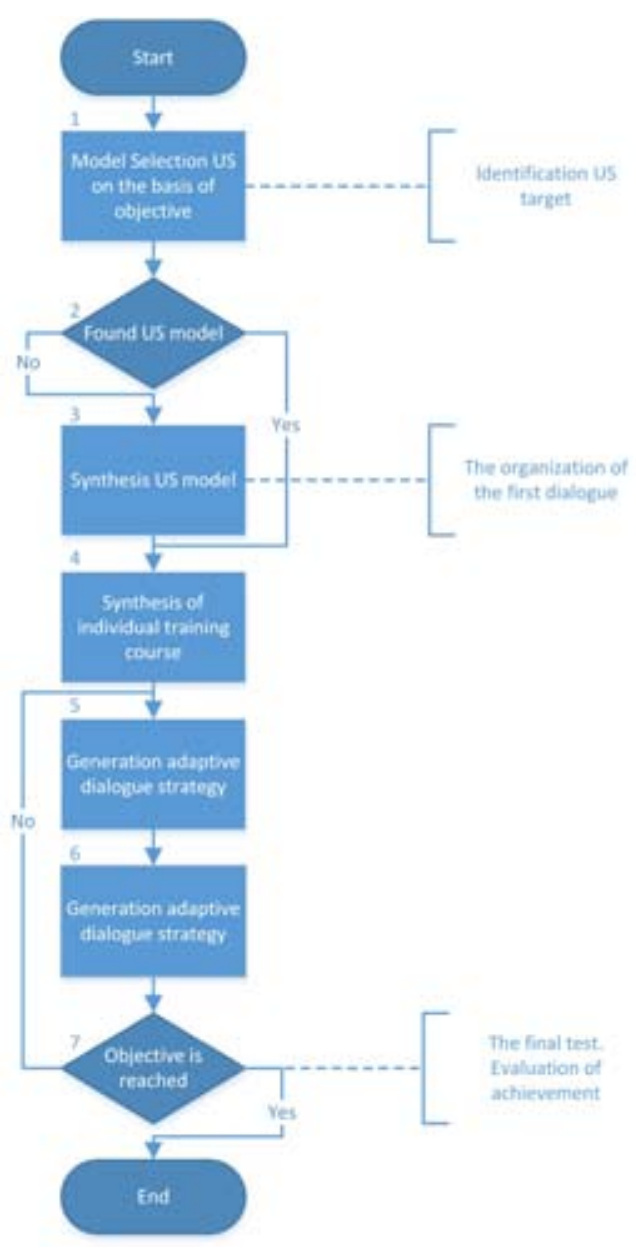

Fig. 3. The algorithm of functioning of the CAO RTS

The algorithm of developed SAE RTS functioning is presented in the Fig. 3. Based on the analysis of the input sentence, that allows to allocate the context and purpose of the US dialogue, and the US model is selected by imposing a one model, that was got during the input test process, and another models, that are in the system database.

After a choice of the US model a synthesis of individual exploration course (IEC) and generation of the strategy of adaptive dialogue are occurred, based on models of the studied subject and US. Four types of dialogue are used in the system: training-dialogue (TD), control-dialogue (CD), workdialogue (WD), access-dialogue (AD). During TD, based on a selected model, the system informs user about theoretical knowledge, that he should to acquire during the self-study process, and provides sequentially material for studying.

If the user wants to check his theoretical knowledge, then the CD type is implemented. The system evaluates the level of assimilation of theoretical knowledge. Implementation of WD type lets to switch on equipment in the interactive mode, to switch modes, to configure, to control an operability on built-in devices using software emulated RTS. That type of dialogue allows to perform operations of work preparation and operational services of RTS. 
AD type allows to evaluate the level of practical skills of the work with technique. The system evaluates US actions during the work as in normal, as in abnormal situation by input of failures with sound signals imitation, switch on/switch off transparences on equipment blocks, changes in indications of devices, etc. That dialogue type can be used, for example, during an admission to independent work on the technique or during a duty on the facility.

On completion of dialogues work the finally test is implemented, and achieving the US aim is evaluated. Based on results of the system tracking of user's actions the US model is synthesized. If the US aim isn't achieved, then US models are compared with the initial. If models are corresponded to each other, then the system reveals new aims (reveals unclear questions) and moves to generation of a new strategy of adaptive dialogue and an implementation of dialogue types. The absence of the US model in database leads to organization of the pre-dialogue, and a new model is synthesized, which is entered in the US SAE RTS database. The new model is generated by averaged parameters and by the most similar models. That choice allows to learn system, and the greater the system "teaches" US, the more accurate models are built.

One feature of this system is the synthesis of IEC, the initial level of theoretical knowledge, practical skills, individual characteristics. The US model as integral part contains a model of US knowledge about studied object, which is contained in the subject area (SA) model and presented as a tuple:

$$
O=<K, S, T>\text {, }
$$

where $K$ - the class of models of studied subject (a type of technique according to classification by a purpose); $S$ - the model of studied subject (of specific technique); $T$ - the time, required for subject studying (of specific technique).

The model of studied subject (of specific technique) can be presented as a graph:

$$
S=\left(W^{s}, R^{s w}, T^{s w}, P^{s w}\right),
$$

where $W^{s}=\left\{W_{i}^{s}, i=\overline{1, n}\right\}$ - topics of studied subject, $n$ - number of topics; $R^{s w}=\left\{R_{j}^{s i}, i=\overline{1, n}, j=\overline{2, n}\right\}-$ a set, which describes relationships between topics of the studied subject; $T^{s w}=\left\{T^{s i}, i=\overline{l, n}\right\}-$ the time, required for studying of a specific topic of studied subject; $P^{s}=\left\{P_{k}^{s w}, k=\overline{1, m}\right\}$ - US profile, $m-$ number of profiles. A weighting coefficient $P_{k}^{s w}\left(0 \leq P_{k}^{s w} \leq 1\right)$ is set by the expert and shows a priority of the k-th studied topic for the specific US. It's clear, that $P_{k}^{s w}=0$, if topics aren't obligatory for that US (for example, specific knowledge), or the input US test showed positive results on this topic $R_{k}^{s w}=1$, i.e.

$$
P_{k}^{s w}=0\left|R_{k}^{s w}=1 ; 0<P_{k}^{s w} \leq 1\right| R_{k}^{s w}=0 .
$$

The model of studied subject is presented as a graph:

$$
W^{s}=\left(Q^{s w}, R^{s w q}, T^{s w q}, P^{s w q}\right),
$$

where $Q^{s w}=\left\{Q_{i}^{s w}, i=\overline{l, b}\right\}$ - questions of the studied topic, $b$ - number of questions; $R^{s w q}=\left\{R_{j}^{s w(i-1)}, i=\overline{1, b}, j=\overline{2, b}\right\}-$ a set, which describes relationships between questions of the studied subject; $T^{s w q}=\left\{T^{s w i}, i=\overline{l, b}\right\}-$ the time, required for studying of a specific question; $P^{s w q}=\left\{P_{k}^{s w q}, k=\overline{1, m}\right\}-$ US profile, $m$ - profile number, $P_{k}^{s w q}$ - weighting coefficient, which shows 
a priority of the k-th studied question for US, and besides $P_{k}^{s w q}=0\left|R_{k}^{s w}=1,0<P_{k}^{s w q} \leq 1\right| R_{k}^{s w}=0$ $\left(R_{k}^{s w}-\right.$ result of input US test).

For the description of a model of the studied question (topic, subject) we will give a definition of the information element (IE), as a minimum, indivisible, logically completed fragment of text (4):

$$
Q^{s w}=\left(E^{s w q}, R^{s w q e}, T^{s w q e}, P^{s w q e}\right),
$$

where $E^{s w q}=\left\{E_{i}^{s w q}, i=\overline{1, d}\right\}$ - IE of the studied question (topic, subject), $d$ - IE number of the studied question; $R^{\text {swqe }}=\left\{R_{j}^{\text {swq(i-l) }}, i=\overline{1, d}, j=\overline{2, b}\right\}-$ a set, which describes relationships between $\mathrm{IE} ; T^{\text {swqe }}=\left\{T^{s w q i}, i=\overline{l, d}\right\}-$ the time, required for studying of IE; $P^{\text {swqe }}=\left\{P_{k}^{\text {swe }}, k=\overline{l, m}\right\}-\mathrm{US}$ profile, $P_{k}^{\text {swge }}$ - weighting coefficients, which shows a priority of the k-th IE for US, and besides $P_{k}^{s w q e}=0\left|R_{k}^{s w}=1,0<P_{k}^{s w g e} \leq 1\right| R_{k}^{s w}=0\left(R_{k}^{s w}-\right.$ result of the input US test $)$.

The SA model allows to make synthesis of IEC. US knowledge about studied subject $S_{z}$ reflect the totality of knowledge and skills, which are necessary for a specialist of this profile. They formalize ultimate aims of exploration, which were set during SAE RTS creation. Model of US knowledge subgraph of the model of the studied subject, i.e. $S_{z} \subset S$, where $S=\left(W^{s}, R^{s w}, T^{s w}, P^{s w}\right)$.

IEC synthesis proceeds as follows. The adjacency matrix is composed for a selected US profile (speciality). Weighting coefficients, which are set by experts of SA, are attributed to apexes of IE. The system synthesizes the exploration course, determining the sequence of studied topics and a diameter structure (maximum path):

$$
D=\max _{i, j} d_{i j}, d_{i j}=\sum_{i=1}^{n} \sum_{j=1}^{m} T_{i j}^{s w q e} .
$$

In this case all IE are considered. The system informs US about time, required for studying the subject. If the time doesn't satisfy US, then he elaborates the task by specifying a profile (speciality). According to selected profile the system synthesizes the exploration course, removing apexes (IE) on the graph with weighting coefficients, that are equal to zero. Besides, apexes (IE) on the graph with weighting coefficients, that are equal to zero after an input test, are removed, if US received a positive mark on that topic. That allows to synthesize the exploration course to a specific person depending on the level of theoretical knowledge and practical skills.

If the time, required for studying the subject, doesn't satisfy US, he can set his own time. Here the system synthesizes IEC, passing sequentially path and removing apexes (IE) with less weighting coefficients, aiming for a specific time. On each step of the synthesis there is a removing of the only one of IE and a comparison the current time with time, given by US. The system adapts to a specific US. For this purpose, the Hurwitz's criterion of finding the shortest path (the optimism-pessimism criteria):

$$
\begin{aligned}
& K\left(a_{i}\right)=\operatorname{\alpha max} T_{i j}^{s w q e}+(1-\alpha) \min _{i j}^{s w q e}, \\
& K_{o p t}\left(a_{i}\right)=\max \left(K\left(a_{i}\right)\right),
\end{aligned}
$$

where $K\left(a_{i}\right)$ - the individual exploration course (the path of apex passing); $T^{\text {swqe }}$ - time, required for studying of IE (studied question, topic, subject); $\alpha$ - optimism coefficient, $0,3<\alpha<0,7$.

It should be noted, that during the process of IEC synthesis it's necessary to know, whether US will be able for a time to learn studied subject to a specified level. For that the coefficient of information 
loss was entered, which is calculated in parallel with the synthesis of IEC. On the first step of synthesis there is the total number of information of the studied subject $H^{s}$, that can be transferred to US during the all course of technique exploration by links, which forms paths of different length. In the system, which consists of $E_{n}$ nodes, the Hamiltonian path [3] is equal $E_{n-1}$, and length of paths between two connected nodes can be from 1 to $E_{n-1}$ :

$$
H^{s}=\sum_{w=1}^{E_{n-1}} \sum_{q=1}^{E_{b-1}} \sum_{e=1}^{E_{d-1}} H^{\text {swqe }},
$$

where $H^{\text {swqe }}$ - the amount of information, contained in one IE. On the second step the total amount of IEC information $H_{k}^{s}$ for the US profile is determined, that can be transferred to US during the all course of technique exploration by links, which forms paths of different length. By the additive convolution method the total amount of information of deleted IE at each step of the IEC synthesis is determined, provided that the weight of EI is equal to zero:

$$
H_{k}^{s}=H^{s}-\sum_{w=1}^{E_{n-1}} \sum_{q=1}^{E_{b-1}} \sum_{e=1}^{E_{d-1}} H^{s w q e} \mid P_{m}^{s w q e}=0 .
$$

As the result, the coefficient of data loss is defined as the ratio of amount of IEC information to the total amount of information of studied subject for the US profile:

$$
Z_{k}^{s}=\frac{H^{s}-H_{k}^{s}}{H^{s}} \mid \quad P_{m}^{s w q e}=0 .
$$

At each step of the IEC synthesis apexes with the lowest weighting coefficients together with links $e_{i} \rightarrow e_{j}$ are deleted, iteratively approaching to a preset time, required for studying the subject. Then the process is repeated with a re-determination of $H_{k}^{s}$ and $Z_{k}^{s}(9),(10)$.

So, the aim of introducing the coefficient of information loss is the evaluation of the possibility to master the subject for a predetermined time to a predetermined level:

$$
P=1-P\left(\mathrm{Z}_{\mathrm{k}}^{\mathrm{s}}\right) \text {. }
$$

\section{Research of SAE RTS effectiveness}

To evaluate SAE RTS effectiveness, we will use a known approach [4], that allows to consider the total effectiveness as the totality of technical and economic efficiency, which are based on performance (practical effectiveness) and in terms of a system approach impact on the total radio-technical support effectiveness of aviation flights. The performance is specified by the functioning quality, that includes reliability of functioning, productivity and functionality (see Fig. 1).

In evaluating of SAE RTS, first of all, we need to know a productivity of the learner, which includes speed and timeliness, and his functional reliability, which includes execution inerrancy, error recoverability. Here evaluated characteristics are speed and execution inerrancy of the operation. The rest characteristics of the functioning quality we will take as constants.

It's advisable to select the following criteria for evaluation: a norm runtime; the number of training sessions to achieve a faultless operation execution for a specified time. 
During the scientific experiment for characteristics evaluation of SAE RTS standard operations were selected, that are used during a preparation of specialists. A one group (experimental) and another group (control) were taken for experiment execution. To achieve the aim of lesson, it was necessary to provide for six hours of lessons, that $90 \%$ of learners could perform norms in accordance with $90 \%$ of error-free execution of operations.

The experiment showed, that, using of two sets of real equipment, learners of the control group are managed to perform necessary operations not more than five times. At the same time, not more than $80 \%$ of learners perform the norm. Using SAE RTS learners of the experimental group performs the norm $5 . .7$ times and not less, than three times on a real technique. At the same time, not less, than $95 \%$ of learners perform the norm.

Comparing results of the experimental and the control groups it can be made the next conclusions: in term of the execution inerrancy of operation the experimental group exceeds the control group on $15 \%$; in term of the number of trainings the experimental group exceeds twice the control group for the same time; $10 \%$ of learners don't achieve aims of trainings; the average time of operation execution in the experimental group is less on $10 \%$.

Since the functionality and performance are private parameters of practical efficiency, then it can be specified as

$$
\dot{\mathrm{Y}}=\sum_{i=1}^{n} \mathrm{a}_{i} \dot{\mathrm{Y}}_{i}
$$

where $\alpha_{i}$-weight coefficient of the private efficiency parameter; $n$ - number of private efficiency parameters. The weight of each parameter is determined by the solved task.

Results of the experiment have showed, that under such results of US preparation the RTS functional reliability increases on $15 \%$. Since the performance is composed of several characteristics, then it increases in total on $10 \%$. For the performance evaluation it's necessary to consider all characteristics of the functioning quality. Under the functionality invariability it can be argued, that this complex parameter increases in average on $15 \%$.

The RTS technical efficiency according to [2] in our interpretation should be assessed as the number of equipment failures caused by service personnel. As the RTS efficiency is evaluated on the functioning step, then it should be considered the all phases of that step. As in this case a technique failure is implied as a consequence of wrong actions of US, then the technical efficiency should be estimated by numbers of its intentional errors. According to [4] the average number of RTS failures as the monoergatic system during the time of the operation execution on technique on the step of its intended purpose use has next form:

$$
m i s_{P T C}=m i s_{m}\left(1+m i s_{p l}\left(1+m i s_{s} m i s_{p r} m i s_{u}\right)\right),
$$

where $m i s_{m}, m i s_{p l}, m i s_{s}, m i s_{p r}, m i s_{u}$, - errors of exploration, planning, service, providing and using.

As the weight of each error during the technique exploration at least three times is greater than the weight of errors during using technique of intended purpose, then a reducing the number of errors on $15 \%$ on the exploration step leads to a reducing the number of RTS human-caused failures on $19 \%$.

$$
-465-
$$


Economic effect from using the SAE RTS technique during the exploration process can be estimated by comparing the value of the technical operation of the radar landing system and SAE RTS during one operation hour, that is $1 / 250$.

As the result of evaluating of RTS efficiency during its using in its life cycle on the step of SAE RTS exploration it was defined, that increase of faultless US functioning on as a part of radio-technical systems on $15 \%$ reduces failures in the system at least on $19 \%$. System performance increases on $10 \%$. And economic effect is increased by 250 times. Practical RTS effectiveness, using SAE RTS, is increased on $15 \%$. Using SAE RTS during the process of personnel training the percentage of failures is changing (Fig. 4). In total, the number of human-caused failures is reduced on $8 \%$.

\section{Conclusion}

The implementation of the method of preparation and retraining of operators of complex RTS by the automated exploration system will allow to reduce errors of RTS operators, and that will affect on the efficiency of the RTS using with a purpose.

\section{Refereces}

[1] Ожегов С.И. Словарь русского языка. М.: Гос. изд. иностр. и нац. словарей, 1953, 848 с. [Ozhegov S.I. Dictionary of the Russian language. Moscow: Gos. izd. inostr. i nac. slovarej, 1953, 848 p. (in Russian)]

[2] Дружинин В.В., Конторов Д.С. Системотехника. М.: Радио и связь, 1985, 200 с. [Druzhinin V.V., Kontorov D.S. System engineering. Moscow: Radio i svjaz', 1985, 200 p. (in Russian)]

[3] Татт У.Т. Теория графов. М.: Мир, 1988, 424 c. [Tatt U.T. Theory of graphs. Moscow: Mir, 1988, 424 p. (in Russian)]

[4] Губинский А.И. Надежность и качество функиионирования эргатических систем. Л.: Наука, 1982, 269 с. [Gubinskij A.I. The reliability and quality of functioning of ergatic systems. Leningrad: Nauka, 1982, 269 p. (in Russian)]

[5] Русов А.И., Машков В.Г., Прохорский Р.А. с. 2015615378 (2015). РФ. 1 с. [Rusov A.I., Mashkov V.G., Prohorskij R.A. s. 2015615378 (2015). RF. 1 p.] 